\title{
Pre-Filtering Mechanism Integrating Gis for Sewer Pipes
}

\author{
Iheanyichukwu C. Nkwodinma*, Mohd Kamarul Irwan Abdul Rahim, Wan Nadzri Osman, Che Azlan Taib \\ School of Technology Management and Logistics, (STML), Universiti Utara Malaysia, 06010 UUM Sintok, Kedah, Malaysia
}

*Corresponding author: iheanyichukwu_chukwu@oyagsb.uum.edu.my

\begin{abstract}
Sewage system which is considered as a way of managing and transporting wastewater from its unhealthy and unhygienic state, treated and recycled to be used for the daily water source activities. It has always been considered that sewer pipe blockage, being a serious problem when it comes to sewage system therefore creating series of backdrop in the form of mosquitoes breeding which causes various diseases, unhealthy environment, and issues of backups in domestic, commercial and industrial buildings. Looking at the rise in population growth, it will prove more hectic and problematic if the sewer pipe blockages are not fully prioritized thereby finding proper ways of mitigating this unwanted catastrophe. In response to this situation, a new concept for mitigating, monitoring and observing the condition within and outside the sewer pipe is being introduced to systematically reduce the problem to a zero minimal tendencies of obstacles that can create a blockage or crack in sewer pipes. A lot of researches have made impacts in mitigating and locating these problems, but this research will be mainly focused on achieving a minimal to zero blockages. Within this context of study, the research is aimed at actualizing the systematic way at which sewer pipe blockage can be avoided or monitored by the use of an effective and efficient wastewater pre-filtering mechanism which the model will be tested to separate wastewater debris and at the same time reduce the FOG (Fat, Oil and Grease) sediments that can cause clogging and then blockage on the long run. The model will function in a way as to automatically deviate or move the waste water debris to a depositing space while the waste water liquid substance is transported via sewer pipe to the central waste water treatment zone integrating geographic information system (GIS) which is the use of spatial analysis in tracking and locating any form of roots or tree growth along the sewer pipe therefore minimising the issues of cracks due to root obstruction etc. Results of the study will be based on Malaysia as a case study.
\end{abstract}

Keywords: GIS, FOG, zero blockages, pre-filter, mitigating, backups

(C) 2016 Penerbit UTM Press. All rights reserved

\subsection{INTRODUCTION}

Malaysia located in the Southeast Asia having a population of about 32 million people, classified as fast developing countries of the world, is still undergoing a process of achieving a central sewerage management system that will connect the whole of Malaysian wastewater origin through sewer pipes to its final wastewater treatment facility centre.

Considering the fact that series of blockages have been reported severally across the country which prompted the need to re-design the way wastewater is transported through sewer pipes to mitigate blockage towards a zero tendency. Here a pre-filtering mechanism between the private sewers pipe which runs from domestic, commercial, industrial, and agricultural buildings and the public sewer pipe is initiated to address the issue of a long term blockage within the sewer pipes.

Sewer pipe blockages are caused mainly by waste water containing Fat, Oil, and Grease (FOG) (Selembo, 2015). Industrial byproduct waste and debris are also included such as solid objects and sanitary pads which often times are carelessly disposed and flushed down the toilet, which accumulate to create blockage within the sewer pipeline. Sewer backups are repercussion of sewer blockages causing wastewater to flow back through pipes into domestic, industrial and commercial buildings creating lots of damages and health hazards. Sewage which is simply described as a wastewater from organic and inorganic substances; which comes as a product of domestic, commercial and industrial waste, disposed through pipelines into sewers, treated to create a healthier environment. The volume of sewage water generated by domestic, industrial and commercial sources have increased along with the increasing population, urbanization, improved living conditions, and economic development (Balkhair \& Ashraf, 2015). Wastewater consists of domestic, industrial and commercial debris in form of faeces, urine, sewage residue or semi solid material found piled up after wastewater treatment, also called a waste within the septic tank.

The application of a pre-filtering system helps in maintaining, managing and as well improving the quality of waste water that flows through the public sewer pipes. It assist in the removal of objects and also the partial removal of Fat, Oil and Grease (FOG) that could in the long run cause blockage, therefore allowing the flow of a filtered waste water running through the sewer pipe to the point of treatment and exit into the river. The application is mainly intended to reduce to a zero tendency the rate at which objects like sanitary pads, and solid objects which are carelessly flushed down the toilet or sink into the sewer pipe and filtered to curb the issues of future blockages. Here the use of Mechanical screen process in the treatment of wastewater is implemented between private sewer pipe and the public sewer pipe since it removes objects such as rags, paper, plastics, and metals to prevent damage and clogging of downstream equipment, piping, and appurtenances (U.S. EPA, 2000), this provide a good way to mitigate future sewer pipe blockages. Therefore a coarse screens which 
has an openings of $6 \mathrm{~mm}(0.25 \mathrm{in})$ or larger is used, and it function in a way as to deposit the debris in a given space while allowing the flow of wastewater through the public sewer pipe. Screening devices are classified based on the size of the material they remove (U.S. EPA, 2000) meaning that its screening diameter is set according to the sizes of the sanitary pads, rags and solids objects meant to be extracted from the wastewater before it gets into the public sewer pipe.

FOG deposits in sewer systems have recently been shown to be metallic salts of fatty acid and identifying the mechanisms of FOG deposit formation could ultimately lead to an improvement in sewer management and maintenance strategies that will reduce blockages caused by FOG deposits (He, X., et al., 2013). Therefore elaborating on the process of neutralizing FOG in wastewater, the suspension of GREASOLUX cartridges within the pre-filtering mechanism is suggested to release powerful fat dissolving microorganisms and enzymes allowing the spread of microorganism within the wastewater, the cartridge which is replaced every 30 to 60days. This helps to neutralize the effects of fat, oil and grease (FOG) within the public sewer pipe therefore minimizing the issues of blockage. The suspension of FOG in wastewater is due to solidification created by a lower temperature within the private sewer pipe which floats and may also be filtered and neutralized by microorganisms released to curb the effect in the public sewer pipe.

Geographic Information System (GIS) which is used to provide a visual representation of results that could be used to communicate the interaction between environmental parameters and both recorded and predicted sewer blockages (Cook, S., et al., 2008). GIS can be used to assess present and future environmental situations around the location of the sewer pipes, therefore avoiding or minimising the problems of obstruction posed by the environmental parameters as in tree roots seeking for water which could cause cracks and blockage within the sewer pipes setting up an overflow and obstruction in sewer services, having an after effects to the building and society.

This research is focused on finding a lasting means of eradicating blockage or at least achieving a minimal to zero blockage level within the public sewer pipes which is cost effective and more efficient to the economic growth of the society.

\subsection{METHODOLOGY}

\section{Research Design}

Technical and constructive plans and measurements will be used to locate the line of flow, public sewer pipeline length to be focused on, and the elevation from the manhole. Esri ArcGIS 10.3 will be used to analyse the sewer pipeline location and a study boundary area will be focused on for consistency and accuracy of flow and also check for any occurrence of an environmental parameter like tree roots seeking for water, geographical earth movement observance. Other data created by company authority will be looked into and also used for research purposes for e.g. Data of the road, river, state boundaries, streets and city locations etc. Here the raster data of the region or area boundary to be analyzed are initialized and interpreted from digitalized aerial photographs or satellites imagery therefore generating an ArcMap of the sewer pipeline location, the drainage, land use, roads and more. ArcCatalog will be used in the creation of geo-databases to store all datasets gotten from Indah Water Konsortium Sdn Bhd Malaysia and the derived analytical results.

The population data of the study area of the segmented populace were downloaded from the population Bureau in tabular form of Microsoft Excel, arranged accordingly and placed into groups then saved as a data file, then saved in the Data management section within the ArcToolBox. Here the study area is checked for which segment of the area is densely and lightly populated to know areas of concentration and closer and broader monitoring of the sewer pipelines. Using distance determinant cost analysis and surface direction for the area of study to determine the most effective cost of routing from the beginning to the final approach.

Figure 1 illustrates the application of a mechanical wastewater screening technology is implemented between the junctions of the private sewer pipes which are smaller diameter sewer pipes, transporting the root wastewater from domestic, commercial, industrial and agricultural buildings and the public sewer pipes which are the huge diameter size pipes mostly placed underground. Through the following Figure 2, the private sewer pipes wastewater is pre filtered with a HUBER Fine Screen STEP SCREEN® SSF combined with HUBER Wash Press WAP® SL for intensive screenings washing with an odour free design (Solutions, n.d.), with the solid objects and organic substance being filtered into a refuse bin for daily collection by the Sanitary agency department, allowing a pre filtered wastewater to be transported into the public sewer pipe.

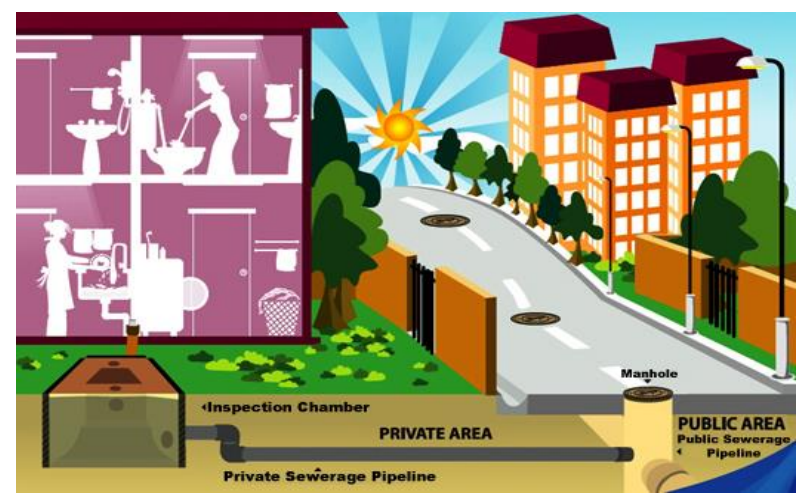

Source (https://www.iwk.com.my/customer/blockages)

Figure 1 The flow of wastewater from a building through private sewerage pipeline into the public sewerage pipeline 

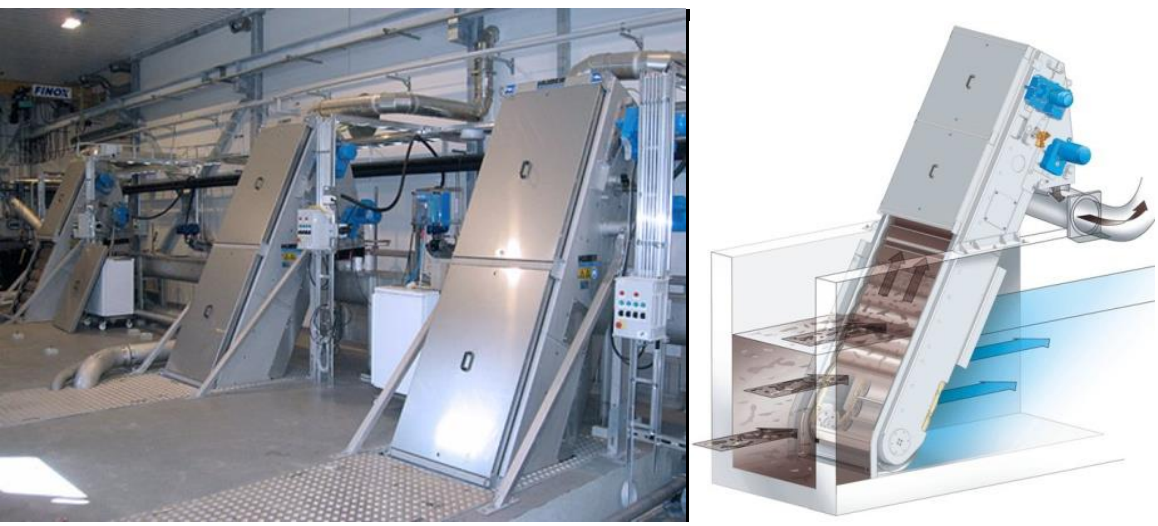

Figure 2 HUBER Fine Screen STEP SCREEN® SSF combined with HUBER Wash Press WAP® SL

The use of GREASOLUX cartridges is also applied by suspending some cartridges according to the quantity of wastewater flow into the HUBER Fine Screen STEP SCREEN® SSF wastewater filtering space, therefore delivering a pre processed wastewater with a minimal effect of FOG into the public sewer pipe.

\section{Research Instrument and Participants}

This research project was developed from reviewing articles, journals, case studies and various reports that show case the challenges, successes of how to make the system functional in Malaysia, results of having an economical, less manned and effective central sewage system. Quantitative methods will be used to analyze the findings therefore using a technique which is statistically descriptive. Data will be collected and created through the distribution of questionnaires and survey to Stakeholders, Users, Experts, Engineers, developers, and Indah Water Konsortium Sdn Bhd Malaysia, with the collection of data from the listed subjects, implementation of a well improved sewage system in Malaysia will be inevitable.

\subsection{RESULTS AND DISCUSSION}

The main idea of study is to create a GIS mapping information technique aimed at monitoring, storing and reproducing data for the management of sewer pipes and its wastewater flow services giving products of an articulated documentation of sewer pipes' environmental parameters condition, geographical earth movement properties, past and recent checks on the spatial analysis of the wastewater flow within the sewer pipes and further checks on gradual improvement after the implementation.

Pre-filtering which is purposefully aimed at doing 'one of the last things first' considering the fact that filtering is mostly the first phase of wastewater treatment, therefore making available the filtering phase of wastewater treatment in the pre filtering process, this research will be able to achieve the objective of having a pre filtered wastewater with less or no solid objects in the thing of sanitary pads, rags etc, and organic substance. Economically, the channelling of wastewater flowing from a combination of different buildings to one set of a pre filtering system will reduce the cost of a acquiring lots of filtering systems.

Finally a GREASOLUX cartridge is tested by suspension of the cartridge into the wastewater to be filtered, what is seen is a release of microorganism and enzymes neutralizing the FOG effect to the sewer pipes therefore mitigating sewer pipe blockage. The cartridge is repeatedly done every 3 to 6 months for an efficient and effective processing.

\subsection{CONCLUSION}

This research addresses the mechanism of pre-filtering with the suspension of an FOG neutralizing agent (GREASOLUX cartridges) within the wastewater pre filtering process phase in sewer pipes. Achieving the goal of mitigating sewer pipe blockage and cracks, the processes aligned herein integrating GIS should be adhered to for an efficient and effective uninterrupted sewerage services.

\section{References}

Balkhair, K. S., \& Ashraf, M. A. (2015). Field accumulation risks of heavy metals in a soil and vegetable crop irrigated with sewage water in western region of Saudi Arabia. Saudi Journal of Biological Sciences, 23(1), S32-S44. http://doi.org/10.1016/j.sjbs.2015.09.023

Cook, S., Boulaire, F., Davis, P., \& Gould, S. (2008). Application of GIS in Understanding and Communicating Interaction between Environmental Parameters and Sewer Blockages, (July), 17-19.

He, X., de los Reyes, F. L., Leming, M. L., Dean, L. O., Lappi, S. E., \& Ducoste, J. J. (2013). Mechanisms of Fat, Oil and Grease (FOG) deposit formation in sewer lines. Water Research, 47(13), 4451-4459. http://doi.org/10.1016/j.watres.2013.05.002

Selembo, G. (2015). Using Acoustic Inspection to Prioritize Sewer Cleaning • Acoustic Inspection Overview • Acoustic Inspection Economics • Case Studies. Solutions, H. T. W. (n.d.). Mechanical wastewater treatment.

U.S. EPA. (2000). Wastewater Technology Fact Sheet Package Plants. United States Environmental Protection Agency, 1-7. http://doi.org/EPA 832-F-99-062 